\title{
Entrevista a Claudia Korol de Pañuelos en Rebeldía. Trayectorias en educación popular, feminista, anticapitalista y descolonizadora
}

\author{
Mariana Smaldone \\ Universidad Nacional de Luján, Argentina \\ intismal@hotmail.com \\ Gisela Manzoni \\ Universidad Nacional de La Plata, Argentina \\ giyitan@yahoo.com.ar \\ Paula Soza Rossi \\ Universidad Nacional de La Plata, Argentina \\ paulasoza11@yahoo.com.ar
}

Claudia Korol es una militante argentina, periodista, educadora popular y feminista, marxista y anticolonialista. Su militancia comenzó en el Centro de Estudiantes de la Escuela Superior de Comercio "Carlos Pellegrini" y luego integró la dirección de la Federación Universitaria de Buenos Aires (1983-1984) y de la Federación Universitaria Argentina (1984-1987). Participó en la Brigada del Café que parte de las brigadas juveniles de solidaridad con Nicaragua y que estuvieron en la cosecha del café (1984) y de las brigadas de solidaridad con Chile durante la dictadura de Pinochet (1984/1985/1986). Como educadora, participó -y continúa haciéndolo- en proyectos de formación política con organizaciones de mujeres, feministas y movimientos de campesinxs y piqueterxs. Coordinó el equipo de educación popular de la Universidad Popular Madres de Plaza de Mayo (2000-2005) y participó en la coordinación de la Cátedra de Formación Política "Ernesto Che Guevara" en la misma Universidad. Ha sido corresponsal de ADITAL (Brasil), Punto Final (Chile), Jornal Brasil de Fato (Brasil), Radio Rebelde (Cuba), el periódico de las Madres de Plaza de Mayo (Argentina), Las Doce, Marcha y secretaria de redacción de la revista América Libre (el director era Frei Betto, 1993-2001). Integra el Equipo de Educación Popular Pañuelos en Rebeldía y forma parte de Ingéneros, un colectivo de trabajo en la Regional Avellaneda de la Universidad Tecnológica Nacional (UTN). Conduce el programa de radio Aprendiendo a volar, en la radio FM La Tecno. Es autora o coordinadora de varios libros, entre los que se encuentran: Rebelión, reportaje a la juventud chilena (1985), El Che y los argentinos (1988), Feminismo y marxismo, diálogo con Fanny Edelman (2001); Gladys Marin (2003), Caleidoscopio de rebeldías (2006), Hacia una pedagogía feminista. Género y educación popular (2007); Somos tierra, semilla y rebeldía. Mujeres, tierra y territorio en América Latina (2016), Feminismos populares. Pedagogías y políticas (2017) y Las Revoluciones de Berta, conversaciones con Berta Cáceres (2018), líder indígena lenca, quien fue coordinadora del Consejo Cívico de Organizaciones Populares e Indígenas de Honduras (COPINH), a quien asesinaron en 2016. Apreciamos la atención que tuvo Claudia al recibirnos en la radio FM La Tribu, 88.7, antes de salir al aire junto con la periodista feminista Liliana Daunes en el programa que conducen, Espejos todavía, el 23 de octubre de 2018.

\section{- ¿Quién es Claudia Korol? ¿Cómo te presentarías?}

Fundamentalmente, como alguien que trata de aportar a las luchas y los sueños de nuestros pueblos, de las mujeres, de las disidencias sexuales desde un lugar específico que es la educación popular, desde la pedagogía 
feminista. También, soy madre de una joven. Una es lo que va creando en vínculos, en las relaciones. Una no es nunca sola. Es en el contexto de todos los vínculos de este tiempo y de los que le tocaron vivir que son bastantes. Entonces, soy con mis compañeras, con mis hermanas de lucha, de vida, de creación.

- En tus libros está presente ese recorrido, sobre todo en los agradecimientos a tus maestras y en la red de intercambios de conocimientos...

Sí, es sobre todo la historia de muchos diálogos. Aprendí mucho del caminar de mis compañeras, de mis hermanas, del diálogo con ellas y del andar juntas. Entonces a veces lo que sale en el libro no es más que un fragmento de esos diálogos. Una de las cosas que reconozco de ese andar juntas es la esperanza de que se pueden cambiar las situaciones de dolor, que seguimos viviendo y que seguramente vamos a vivir. Tenemos mucha confianza en nosotras, mujeres, pueblos, rebeldes, para salir de cualquier situación.

- ¿Cómo comenzó tu militancia feminista?

Yo siempre digo que, en realidad, no llegué al feminismo por la lectura, ni escuchando a intelectuales feministas, sino por chocarme a partir de la militancia en distintos espacios -y casi siempre desde la perspectiva de la educación popular- con situaciones que yo no sabía cómo nombrar, no entendía por qué sucedían. Busqué respuestas, entonces sí, en los libros y en diálogos con compañeras feministas, y entonces, supe qué era el patriarcado y supe que había un pensamiento y una práctica nacida del movimiento de mujeres que es el feminismo me ayudó a entender muchas de esas situaciones. Por los años '90, por ejemplo, empecé a hacer educación popular con colectivos de campesinos y campesinas. Algo que siempre me preocupaba era la dificultad de participación que tenían las mujeres campesinas en sus propias organizaciones. $\mathrm{O}$ cuando podían participar, varias después dejaban de venir a los talleres. Me preguntaba por qué. Fui conociendo junto a ellas lo que implica el lugar de la mujer en el campo, en un lugar donde el machismo es tan fuerte. Ese tipo de experiencias me llevó a hacerme muchas preguntas. Yendo así desde la práctica, a la lectura y a los diálogos con el feminismo pude ponerle nombre a muchas injusticias y a muchas resistencias.

- Esta forma de acercarse al feminismo, desde los interrogantes ¿es una cuestión generacional?

Sí, en mi caso, sobre todo en la etapa post dictadura, se abrió un espacio para la lucha feminista. Nos sentimos, por un lado, muy convocadas; por otro lado, problematizamos cuestiones de nuestra militancia anterior, violencias patriarcales que habíamos naturalizado en nombre de la lucha contra la dictadura y por el socialismo. Sobre todo, abrimos los ojos a cuestionar los machismos y las presiones aún dentro de las militancias que creíamos socialistas. Fue muy interesante no desmoralizarnos sino encontrar respuestas en el feminismo y asumir esa militancia.

- En el libro y en el diálogo con Fanny Edelman, Feminismo y marxismo, se pone de manifiesto la cuestión de las búsquedas dentro del movimiento y la militancia de izquierda...

Sí, para mí, Fanny fue una de las maestras importantes que tuve. Y es extraño porque ella, una dirigente del Partido Comunista, estaba absolutamente disciplinada en los códigos de la militancia de esos tiempos, que incluso no eran los mismos tiempos míos, sino anteriores. Ella comienza sus andanzas en el siglo XX, en la guerra civil española y fue brigadista internacional. Así y todo, ella tenía una luz que le permitía una mirada crítica que la llevó a acercarse al feminismo. Trabajamos juntas en dos libros. Para mí fue un gran aprendizaje.

Incluso, a pesar de que yo me alejé del Partido Comunista hace ya hace muchos años, y que a ella le dolió mi decisión en ese momento, pude conservar un nivel de diálogo, confianza, cariño, y continuar esa forma de aprendizaje. A Fanny le gustaba mucho el diálogo con otras mujeres. Uno de los últimos diálogos que tuvimos fue con Berta Cáceres. Estuvimos toda una tarde con Berta en la casa de Fanny. Ella tenía que operarse y, aun estando muy grave, no quiso renunciar a hablar con Berta; le preguntó sobre lo que hacía y acerca de los debates que había en su Honduras. De Fanny aprendí eso del diálogo a pesar de las diferencias.

- Siguiendo con la militancia feminista ęcuándo y cómo fue tu primera participación en el Encuentro Nacional de Mujeres y también en los Encuentros Regionales, por ejemplo del Oeste y Noroeste del Gran Buenos Aires? 
Mi primer Encuentro fue en Rosario (2003). Me acuerdo, también, de participar en algunos Encuentros Regionales en el Oeste. Ahí aprendí mucho de algunas compañeras como Zulema Palma [de Mujeres al Oeste] ${ }^{1}$ y Cristina Coronel [de Mujeres al Pie del Cañón, organización feminista de Moreno], compañeras muy queridas que nos interpelaban a las de la capital. Cada vez que pude fui al Encuentro Regional, porque reconozco que lxs del Oeste tienen una fuerza especial. Me acuerdo mucho del encuentro en FM La Tribu en el 2000, donde estuvieron muchas compañeras pioneras en la lucha feminista, como Safina Newbery, Marta Rosemberg, Liliana Daunes, Diana Maffía, Zulema Palma, entre otras. Uno de los acuerdos fue crear una agencia de formación de mujeres, que después se llamó Rima. Hablamos de la necesidad de generar redes de comunicación entre nosotras, saltar el charco y que las de capital vayamos a los otros territorios, aunque mi experiencia siempre había sido moverme en los territorios. No tanto desde la experiencia feminista si no desde mi participación en la Federación Universitaria Argentina, un vivir rotando de acuerdo donde estaba el conflicto universitario.

- Respecto de tus profesiones ¿̇tenés formación como periodista y también como docente o de educadora-popular?

Mi formación, en todo, es autodidacta. En realidad, estudié economía política en la UBA, pero me agarró la dictadura en el medio de la carrera, caí presa, y ya no pude seguir... Me anoté a estudiar economía porque estaban cerradas las carreras que a mí me interesaban, las de ciencias sociales. En esa omnipotencia de la juventud dije "bueno, ahora hago economía que es una base para cualquier otro análisis... cuando derrotemos a la dictadura, haré otras carreras". Pero cuando la dictadura se retiró, ya no quise volver a la universidad. No tengo una profesión universitaria. Como periodista me fui haciendo en el camino, por la necesidad de comunicar. La que creo que es mi formación más sistemática - pero no en marcos institucionales- es la de educación popular, que tampoco estudié en ningún lado, sino haciéndolo en la interacción con muchas compañeras y compañeros con mucha experiencia de toda Latinoamérica. En la primera etapa que hice educación popular, recibí mucho apoyo y formación de compañeros y compañeras de Brasil, del Movimiento Sin Tierra, de gente de Centroamérica.

- ¿Cómo y cuándo surge la idea de pensar y educar desde la pedagogía popular y feminista? Esta pedagogía, ¿constituye una herramienta-pedagógica para luchar ante la violencia contra las mujeres? ¿En qué sentido?

Empecé haciendo educación popular sin una mirada feminista. La fui adquiriendo en la práctica misma, para tratar de responder a las preguntas que nos hacíamos con las mujeres de los movimientos populares. En los años '90, formamos un equipo de educación popular que se llamó “Juana Azurduy”. Después en el marco de la Universidad de las Madres, fuimos creando otro equipo que cuando nació era el equipo de Educación Popular de la Universidad de las Madres y luego llamamos Equipo de Educación Popular Pañuelos en Rebeldía. El ponerle nombre (Pañuelos), fue fruto de ir pensando la autonomía como un eje fundamental de nuestra pedagogía, lo que también nos tenía que atravesar a nosotrxs. Así fue que asumimos ese nombre y, después, en el caminar, fuimos relacionándonos con el feminismo y asumiéndolo como pedagogía propia, una pedagogía feminista, descolonizadora y anticapitalista desde una perspectiva socialista. Las mujeres de Pañuelos empezamos a ser parte de distintos espacios feministas. Hay una cuestión general que atraviesa los procesos de formación feminista y cualquier proceso de formación popular, cómo nosotras trabajamos desde los cuerpos y desde los territorios. Pensamos que las violencias son formas de organizar la dominación ya sea capitalista, patriarcal o colonial. Pero después, como parte de nuestras iniciativas, las Mujeres de Pañuelos fuimos haciéndonos parte de la Campaña Nacional por el Derecho al Aborto Legal, Seguro y Gratuito y la Campaña contra las violencias hacia las mujeres. Fuimos asumiendo una mirada más específica en el tema de la violencia contra las mujeres, y al mismo tiempo fuimos aprendiendo las luchas de las disidencias sexuales, con maestras como Lohana Berkins y Diana Sacayan. Cuando estalla el Ni una Menos, donde se generaliza esa temática y estalla el proceso de crecimiento de esta ola o de esta marea feminista que problematiza todas las dimensiones de la vida, ahí tuvimos, necesariamente que pensar con mucha más profundidad todos los temas 
que hacen a la violencia. También, comenzamos a tener una mirada histórica desde la crítica al colonialismo y de cómo eso se expresó en nuestro continente de genocidios y de violencia sexual contra las mujeres. Pudimos profundizar para entender no solo el fenómeno último que es la violencia directa física, aquello que se expresa en el feminicidio contra lo cual reacciona el movimiento de Ni una Menos, y que nos parece maravilloso que haya sucedido. Tuvimos que hilar más fino en cuanto a los "orígenes" de esa violencia y no verlo como la perversión de tal tipo sino como un sistema y una cultura propia del mismo, que construye a esas personas y legitima esas violencias. Así, en la última etapa hicimos una experiencia muy interesante en la articulación con otras organizaciones feministas de Abya Yala. En esta articulación con otras compañeras, iniciamos un juicio al sistema de justicia patriarcal. Si bien nosotras ya lo teníamos como hipótesis, al exponer y escuchar caso sobre caso, pudimos entender cómo la justicia es patriarcal y legitima violencias. Esto nos atravesó muy fuertemente en nuestra propia subjetividad y en nuestros propios cuerpos, y fue una experiencia política de denuncia de la justicia patriarcal, pero también muy pedagógica para nosotras.

- En relación con las prácticas pedagógicas ¿̨cuáles son las bases teóricas o quiénes son sus referentes? Y ¿qué es hacer pedagogía feminista en la actualidad, en el día a día? ¿Cómo? ¿Con quiénes?

En general, una tiende a ubicar cuatro o cinco referentes teóricos y tranquilizarse, pero a mí me enseñaron mucho las compañeras indígenas, negras, campesinas, villeras, trabajadoras, las madres que buscan a sus hijas e hijos, las abuelas, las defensoras de territorios, porque sus prácticas interpelaron las teorías -las que yo tenía o las que teníamos como colectivo-. Por ejemplo, las Madres de Plaza de Mayo son un ejemplo por su lucha, y también, son una interpelación a núcleos muy duros del patriarcado como el concepto de una maternidad individual, casi privada. Cuando las madres dijeron "socializamos la maternidad", nos preguntamos “'y eso qué es?”. Son las madres de todos y todas lxs que luchan. Después, hay movimientos que nos enseñaron mucho, como el Movimiento Sin Tierra de Brasil y las organizaciones campesinas que plantearon el debate y realizan experiencias de soberanía alimentaria, algo tan importante para nosotras, nosotros, nosotres, como es el tema de la alimentación en este tiempo. El cuidado de las semillas lo aprendí de las organizaciones campesinas. El movimiento piquetero o de las fábricas ocupadas por trabajadoras/es, nos permitió grandes debates teóricos sobre el concepto de trabajo. El feminismo revolucionó las teorías sociales y está revolucionando al mundo. Después, puedo nombrar un montón de referentes como Paulo Freire, Rosa Luxemburgo, Antonio Gramsci, el Che, Angela Davis. Pero parte de lo que aprendí es que hay creación colectiva y conocimientos que tienen una densidad muy grande, que a veces lxs intelectuales teóricxs pueden expresarlo muy bien, pero la posibilidad de crear esas ideas y de amasarlas o de bordarlas o de tejerlas la tienen los pueblos, y las mujeres de los pueblos. Aprendí mucho de las feministas comunitarias de Guatemala, sanadoras ancestrales que utilizan toda su sabiduría al servicio de la sanación incluso en temas tan fuertes como la violencia sexual, la sufrida en las dictaduras y las guerras. Las mujeres han conservado la memoria de los saberes y las transmiten. Aprendo cada jueves que voy a la Plaza de Mayo, cuando escucho las palabras de Norita Cortiñas y Mirta Baravalle. Aprendí mucho escuchando la palabra de Ramona y de las mujeres zapatistas. Aprendo ahora que voy conociendo a las mujeres kurdas y a sus líderes históricas como Sakine Cansiz. Hay una genealogía de mujeres que son invisibles desde el punto de vista de su reconocimiento como teóricas pero que en la transmisión de la cultura, de la identidad y de los saberes del pueblo son decisivas. Una de mis maestras más amadas ha sido Berta Cáceres. Recuerdo un diálogo que tuve con ella cuando estaba luchando por impedir la instalación de la represa Agua Zarca en el río Gualcarque. En la primera etapa de esa lucha de la comunidad lenca de Río Blanco, se enfrentaron a la empresa hondureña DESA [Desarrollos Energéticos S.A.] y a otra empresa china, Sinohydro. Yo me agarré la cabeza y le dije: "pero Berta, ¿cómo se te ocurre ir contra los chinos que tienen tanto poder? Acordate lo que le hicieron a los vietnamitas". Ella me respondió con todo ese saber de la ancestralidad, de la realidad, de la lucha del pueblo... "Compita, la lucha la hace el pueblo. El pueblo lenca ya dio muchas batallas. Somos parte del territorio. Somos el río, ahí están nuestros espíritus”. Berta, en esa batalla, dejó su vida, pero el pueblo lenca sigue luchando y todavía no se pudo instalar la represa. Sinohydro se fue. Son lecciones de vida que unx aprende. No sólo aprendemos 
teorías, también valores como la dignidad, y sentidos vitales, como la esperanza. Berta decía: "nos pueden matar a nosotros, pero el pueblo sigue la lucha". Aunque la extrañemos tanto a Berta, y aunque nos parezca que tendría que haber vivido más para poder seguir dándonos elementos, ella nos dio lecciones y nos sigue dando. El hecho de que su organización, el COPINH, siga de pie, que el movimiento no haya muerto con ella, que se siga defendiendo el río Gualcarque, es parte de las lecciones que sigue dando aún más allá de su vida. Seguramente, nadie la va a poner entre las teóricas del siglo XXI, pero para mí lo era, como parte de la legión de las "teóricas prácticas", en una genealogía de mujeres rebeldes, en la que se inscriben también Betty Cariño, compañera mixteca, educadora popular, asesinada en México en 2010, Marielle Franco, activista negra, lesbiana, feminista, asesinada en 2018. Son compañeras que han hecho pedagogía del ejemplo. Hay muchas compañeras en el pueblo mapuche, en los pueblos originarios, negro, entre las trabajadoras urbanas y rurales que vienen haciendo camino muy anónimamente, y constituyen colectivos con mucha fuerza y mucha creatividad.

- Entonces ¿qué significa "comunidad educativa” desde la educación popular, feminista y decolonial?

En la educación popular, un tema muy importante es que el sujeto del proceso educativo es el grupo, la comunidad. No lo son los o las estudiantes o educadores, sino la totalidad de quienes formamos parte de ese momento pedagógico. Si estamos hablando de una escuela en concreto o de la universidad, es también todo lo que rodea a estudiantes, a educadores, no docentes, el barrio, el territorio, la familia. Hace poco, hicimos un taller en la localidad de Moreno, en la calle, frente a un colegio que estaba en paro exigiendo justicia por Sandra y Rubén, compas ${ }^{2}$ de la escuela primaria No 49 “Nicolás Avellaneda”, que perdieron la vida el 2 de agosto de 2018 cuando se produjo una pérdida de gas en un contexto de desidia y abandono del gobierno provincial. Estábamos dando clase en la calle. Los vecinos y las vecinas se detenían a escuchar. Había estudiantes, docentes. Son comunidades con muchas contradicciones, pero siempre el sujeto del proceso pedagógico es la comunidad. Esta cuestión es fundamental para pensar los procesos de enseñanza y aprendizaje, como un proceso por un lado dialógico, donde la propuesta misma sea pedagógica y política. Toda propuesta pedagógica es política. Sabemos que los programas educativos de la educación pública están sugeridos por el Banco Mundial, y ejecutados por el Ministerio de Educación de turno, que pretende que los/las educadores/as se subordinen a sus pautas. Pero en la práctica educativa concreta es posible desafiar el chaleco de fuerza de esos programas y atreverse a pensar otras construcciones posibles... Yo siempre cuento una experiencia que es medio extrema, pero la aprendí en Guatemala, haciendo educación en el medio de la guerra, que se creía que iba a ser una guerra prolongada, con compañeros y compañeras que estaban en la Unión Revolucionaria Nacional Guatemalteca, y se preguntaban, por ejemplo, cómo se enseña matemática desde la educación popular. Siempre está la idea vulgar de que la educación popular puede ser para tratar unos temas sociales, o para la educación básica, para alfabetizar, pero no para abordar los temas de las ciencias "duras". Los y las compas de Guatemala nos decían: "es muy fácil, el aprendizaje tiene que ver con la necesidad". Entonces planteaban problemas como éste: "Si estamos acá ubicados, y el ejército que está a tantos kilómetros viene avanzando hacia nosotros/as a tal velocidad: “¿a qué hora tenemos que irnos de acá para seguir viviendo?”. Esto muestra qué tan relacionado está el conocimiento con la necesidad, porque en este caso no podían equivocarse... Así aprendieron matemática con mucha precisión. También pienso como ejemplo cuando las compañeras zapatistas tuvieron que pensar cómo relacionarse con el mercado, "afuera”, y tuvieron que aprender no sólo sobre esos números, sino sobre todo cómo defender sus territorios; tuvieron que aprender algunos elementos que tienen relación con los saberes, con las necesidades concretas, como también con el reconocimiento de las diversidades. De este modo, pienso que es la comunidad la que va estableciendo cuáles son esas necesidades. Entiendo que en la escuela pública eso es difícil, porque está la presión de los tiempos, que las maestras y los maestros están absolutamente precarizados/as, y que tienen poco espacio para ese diálogo en y con la comunidad y a veces hasta para sentirse comunidad -además de que no son formados para eso-. En general, lxs docentes son formados para sentirse superiores a quienes supuestamente no saben nada, pero el ejercicio de ese diálogo es lo que les permite, en la medida en que lo van haciendo, 
crear otros modos de educación y además pensar que esos modos de comunicación. Son modos de enseñanza y también de aprendizaje.

- Además del trabajo en la UTN-Avellaneda, como comentaste, y al tener en cuenta además la experiencia del taller "Pedagogía feminista para el abordaje de las violencias" que brindaron en las Jornadas CInIG de Género y Feminismos en 2018, ¿̇sostienen este tipo de vínculos e intercambios con otras instituciones educativas?

Sí, hemos hecho son muchos talleres dentro de la universidad. Interpelándonos e interpelando la construcción de saberes, discutiendo por ejemplo qué significan las "disciplinas". Nos preguntamos qué relación tiene la división de saberes con las necesidades de nuestros pueblos; qué, cómo y para qué se aprende. Vimos enormes posibilidades de hacer acciones comunes tanto con estudiantes como educadores y educadoras que tienden a desconolizar las propuestas educativas universitarias, a tratar de mirar cuánto tienen de eurocéntrico en su construcción y cómo reformular dentro de esos espacios que ofrece la creatividad dentro de la academia que no es fácil, sobre todo al conocer los límites de la academia. Así, hemos hecho varios talleres que trataron de ir problematizando esos sentidos. Si bien no es lo prioritario que estamos haciendo, porque con Pañuelos en Rebeldía nuestro trabajo central es la formación de militantes con los movimientos populares, nos interesa mucho hacer este trabajo con la universidad y en espacios de la educación pública. Creo que hay un campo muy grande tanto como para problematizar como para pensar nuevos caminos de creación de saberes. En algunos momentos hicimos cursos como cátedras libres en algunas universidades, sobre todo en el interior del país. Ahí hay un espacio también de actuación que no es sistemático porque no lo tenemos organizado de ese modo pero que nos interesa explorar. Tenemos además un área de investigaciónacción participativa, donde hemos hecho distintos procesos de investigación sobre temáticas que nos parecían relevantes. Algunas veces, lo hicimos en colaboración con cátedras universitarias. Por ejemplo, realizamos todo un estudio sobre la lucha piquetera en General Mosconi en colaboración con la cátedra de psicología social comunitaria de la UBA. No aceptamos la jerarquía que propone la academia que desvaloriza la educación popular, pero tampoco hacemos una jerarquización inversa. Creemos en el diálogo de saberes.

- Ya nos hablaste de Pañuelos en Rebeldía, podés detallar ¿Qué es y cómo nace Pañuelos en Rebeldía? Y ęcuál es la formación y conformación de lxs compañerxs que integran la organización?

Pañuelos en Rebeldía nace en el marco de la Universidad de las Madres de Plaza de Mayo. Ahí empezamos, junto con Mirta Israel, abriendo lo que las Madres llamaron una "carrera de educación popular", aunque nosotras decíamos: "bueno el nombre carrera no le queda", pero no había cómo pelearse con las Madres. Era un proceso de formación de tres años donde fueron formándose lxs primerxs compañeros y compañeras que se fueron integrando en el equipo de coordinación de la "carrera" de educación popular de la Universidad de las Madres. Ya por el año 2003 empezamos a pensar si seguir siendo parte de la universidad, porque se abrían grandes diferencias políticas y metodológicas. En diciembre de 2004, decidimos el nombre: Pañuelos en Rebeldía. Fue en el marco de un aniversario del 19 y 20 de diciembre de 2001. Estábamos en medio de una marcha y como la marcha iba de la universidad hasta la plaza tuvimos bastante tiempo. Íbamos caminando y se fueron tirando varios nombres. Quedó "Pañuelos en Rebeldía". La mayoría de los compañeros y las compañeras que son parte actualmente del equipo, realizaron los procesos de formación que se hicieron en ese marco, o después en el espacio que ahora tenemos en Pompeya o en diferentes territorios del país, como Rosario, La Plata, Córdoba, Tandil, Mendoza, Zona Norte, Oeste, Sur, del conurbano, etc. Lxs compañerxs que son parte de Pañuelos tienen que haber pasado por el proceso de formación de dos años, y aportan saberes que traen de otras experiencias y que aportan en los procesos de formación.

- ¿Cómo sería militar o activar en Pañuelos? ¿Cómo funciona la organización y qué alcance tiene a nivel local, nacional y latinoamericano?

Nosotrxs, como equipo de educación popular, somos parte de una corriente que piensa a la educación popular como una pedagogía de la resistencia, la rabia y la lucha contra todas las opresiones; una pedagogía "de" los oprimidos y oprimidas, y no "para" lxs oprimidxs. Tiene como sujetos a lxs oprimidxs organizadxs, 
luchando para superar esas opresiones, luchando por la emancipación. No creemos que la tarea de la educación popular sea "facilitar" el aprendizaje, sino complejizarlo; poder incluir en los procesos de aprendizaje las dinámicas colectivas, las dinámicas grupales, las dinámicas y procesos que apuntan a tratar de mirar la realidad que queremos transformar con toda la complejidad que tiene. Para que sea así no se trata solo de leerla de los libros sino de interactuar en esa realidad. Por eso somos parte del activismo político, social, militante. El proceso de aprendizaje no es solo un proceso de lectura racional, también tratamos de involucrar el juego, el arte, el psicodrama, el sociodrama, los sentidos, los afectos, y en la medida en que fuimos también profundizando la ideología feminista, una perspectiva que incluye el abrazo, que incluye toda la dimensión del cuerpo. Es una apuesta de vida. No podés hacer eso y después volver a tu casa y olvidarte de todo. Entonces, tiene la exigencia de pensarnos no solo como educadores y educadoras, sino sobre todo como gente que está aprendiendo todo el tiempo. Esos aprendizajes son dolorosos, son compromisos que adquirimos en un aprendizaje. Mucho tiempo hemos realizado talleres en cárceles y decíamos, es muy difícil, es ver brutalmente la realidad de las injusticias ahí, y además la impotencia. Trabajábamos con mujeres que tienen prisión perpetua por defenderse de la violencia patriarcal: ¿cómo les vas a hablar de educación como práctica de la libertad? La educación popular es interpelarnos permanentemente, pero también en cómo somos en nuestra vida, en nuestra casa, si hacemos pedagogía afuera o también adentro, cómo somos en nuestras relaciones amorosas. No podemos dar clases de Educación Sexual Integral (ESI) y después llegar a nuestra casa y olvidarnos. Cuando digo ESI, digo la vivencia plena de la sexualidad, por ejemplo. En ningún ámbito nos preparan para todo eso, ni en la universidad, ni en la familia. Es muy desafiante, nos genera mucho compromiso. A veces mucha angustia y mucha alegría también, porque vamos creciendo colectivamente, aprendiendo unxs de otrxs. Un espacio en el que venimos participando y aprendiendo mucho, es el de las feministas de Abya Yala; allí hay compañeras de Guatemala, Bolivia, Colombia, Paraguay, de Kurdistán, de Honduras y de casi toda Latinoamérica. Estamos al día de lo que pasa en Honduras, de lo que pasa en Guatemala, en Venezuela, en Colombia, en Cuba y en otros lugares que queremos.

- Claudia, nos hablaste de varias experiencias pedagógicas ėalguna otra experiencia que recuerdes en relación con la tarea de educar-enseñar-aprender desde la perspectiva de la pedagogía feminista y popular?

Me vienen a la memoria muchas experiencias que no son propias. En particular, dos lugares en los que viví fascinada. Uno, ya lo nombré, es en Honduras: la experiencia junto a Berta y la forma de organización en el COPINH. Estuve en un encuentro que ellas organizaron, conjuntamente con otras organizaciones, a pocos días de comenzar la dictadura en Honduras. Allí se reunieron a más de mil delegados y delegadas de distintas organizaciones para discutir cuál era la Honduras que querían. Una pensaba que estaban apenas viendo cómo resistir, pero no, estaban pensando qué Honduras soñaban: qué agricultura, qué hacer con las fuerzas armadas, qué hacer con los ríos, qué hacer con el agua y la espiritualidad. Un encuentro maravilloso en el que terminaron con propuestas para la refundación de Honduras. Cuando le pregunté a Berta de qué se trataba ese encuentro, me dijo “compa, es una experiencia pedagógica, usted debería saberlo". Como éstas, tengo presente otras experiencias educativas como las del Movimiento Sin Tierra (MST) en Brasil, donde emociona ver cómo el feminismo fue creciendo y hoy afirma que "sin feminismo no hay socialismo". Dentro del MST hoy están organizadas no sólo las mujeres sino también las disidencias sexuales, algo impensado en un movimiento con fuertes raíces machistas. Otra experiencia que me resultó increíble fue la de los y las zapatistas. Tuve la suerte de participar en la fundación de una escuela zapatista en el medio de la Selva Lacandona, en Chiapas. Allí se piensa la educación verdadera desde las necesidades de los olvidados y olvidadas. Hay un montón de mundos invisibles, maravillosos, creativos, que desafían las lógicas más violentas y despiadadas y que sin embargo siguen caminando. Por suerte no se ven mucho, porque si se ven un poco más, los van a tratar de destruir. Esto nos tendría que dar mucha esperanza, a pesar de los golpes que vamos recibiendo. Esto me dio y me sigue dando una experiencia en términos de aprender a no manejarnos con lo superficial o con lo inmediato solamente. Siempre cuento que conocí a Paulo Freire en los años '90, cuando 
todo el mundo de las izquierdas estaba desesperanzado, porque se había caído el muro de Berlín y calado muy fuerte el discurso del fin de la historia y el fin del socialismo. Freire había publicado Pedagogía de la esperanza y yo fui a entrevistarlo. Pensé que era un loco porque cuando todo el mundo estaba llorando y lamiéndose las heridas, él estaba hablando de "pedagogía de la esperanza". Ese encuentro a mí me dio mucha fuerza. Interioricé el sentido profundo de la dialéctica revolucionaria. Freire no hablaba desde una posición religiosa de la esperanza o idealista, sino que él hablaba desde una mirada dialéctica de la historia. Después lo fui sintiendo en otras experiencias y ahora la emergencia del feminismo como marea. No podemos hablar del Ni una Menos sin mirar esa historia nuestra que tiene más de cinco siglos de lucha de las mujeres y ahora irrumpe con esta fuerza incontenible. Cuando en junio veía toda la movida en la Plaza Congreso, me acordaba de Dora Coledesky que, con pocas compañeras más, juntaban firmas por la legalización del aborto, con una mesita en la esquina del Congreso. Pensaba: Dora no lo vio, pero este movimiento tiene su huella. Es algo para pensar en los feminismos actuales, que mataríamos con los individualismos, que a veces se expresan como espacios de búsqueda de reconocimientos individuales. El feminismo fue un movimiento de grupos grandes y pequeños de mujeres, primero, y después también de disidencias. Hay Lohanas en el camino, hay Dianas. Yo lo veía este año en la marcha travesti y trans en el Encuentro de Mujeres y decía "bueno, no están ni Lohana ni Diana, que son las que iban primero solas a esos encuentros". Hoy otras compañeras travas y trans están ahí, incluso muchas que no somos travas sentimos como propia esa lucha. Por suerte su lucha nos involucró a muchas y son verdaderos procesos históricos colectivos.

\section{Notas}

1 Puede consultarse, Manzoni, G., Smaldone, M., \& Soza Rossi, P. (2017). Entrevista a Zulema Palma y Julia Medina, integrantes de Mujeres al Oeste. Descentrada, 1(2), e027. Recuperado de https://www.descentrada.fahce.unlp.edu.ar/ article/view/DESe027

2 Nota de edición: compas es una expresión coloquial en el ámbito de la militancia en Argentina para referirse a compañeras y compañeros. 